\title{
A coupling method for simulating tunnel excavation with block, particle and bar elements
}

\author{
Xiaoguang $\mathrm{Li}^{1,2}$, Changhong $\mathrm{Li}^{1}$, and Chun Feng ${ }^{3, *}$ \\ ${ }^{1}$ Department of Civil Engineering, University of Science and Technology Beijing, Beijing 100083, China \\ ${ }^{2}$ Dongcheng District Committee of the Communist Youth League, Beijing 100007, China \\ ${ }^{3}$ Institute of Mechanics, Chinese Academy of Sciences, Beijing 100190, China
}

\begin{abstract}
Excavation of tunnel in rock mass refers to complex continuum-discontinuous processes. For capturing the damages of side walls and the supports of bolts/cables, different types of elements shall be used in the same framework. In this work, a novel method is proposed which couples block, particle, and bar elements for simulating the intact rock mass, the broken rock mass, and the supporting system respectively during tunnel excavation. Brittle Mohr-Coulomb fracture constitutive law and tensile fracture constitutive law are introduced for describing the contact behavior between different parts. Penalty springs are adopted for accounting the pre-stresses effects. Moreover, for assuring the proper transitions of forces and displacements between different types of elements, an interpolation coupling approach is presented. Cases considering different tunnel sections and supporting strategies are numerically studied, indicating the reliability of the method.
\end{abstract}

\section{Introduction}

Tunnel excavation in jointed rock mass with high ground stress may result into fracture, fragmentation, even collapse of the surrounding rock. The combined supports of lining and bolt are effective strategies for improving the stability of tunnel. A lot of research work has been carried out on the stability of surrounding rock $[1,2]$, rock burst [3-5] and evaluation of different support strategies $[6,7]$.

Numerical simulation is an effective approach to reveal the failure mechanism of tunnel under complicated trigger factors, and it is also a useful way to evaluate the rationality of tunnel design and construction scheme. Finite element method (FEM), finite difference method (FDM) and discrete element method (DEM) are three useful approaches to execute such simulation.

Recently, lots of studies are concentrated on the combination of FEM(FDM) and DEM. Huang introduced a two-dimensional (2D) coupling analysis method by employing the commercial codes FLAC for FDM and PFC for DEM simultaneously [8]. In Huang's method, the potential damage zone was discretized by particles, and the intact surrounding rock was discretized by elements. Yang [9] and Saiang [10] also adopted FDM and DEM to simulate the large deformation and damage zone around a tunnel boundary. Lisjak [11] studied the stability of circular excavations in clay shales by the combined finite/discrete element method (FEM/DEM), and the modelling results highlight the importance of shear strength mobilization along bedding planes in controlling the excavation damaged zone formation process. Liu [12] developed a GPU accelerated NMM, and a series of tunnel excavation models were simulated to show the efficiency and capability of this method for modeling the formation of the excavation damaged zone in deeply buried rock tunnels.

FEM(FDM) is good at representing elastic and plastic deformation of surrounding rock outside the loosening zone, and DEM is suitable for describe the damage and fracture of the rock inside the loosening zone. Although lots of numerical studies related to tunnel excavation and support had been done, FEM and DEM coupled tunnelling simulation under rock bolt support is parely referred. Thus, a block-particle- bar coupled algorithm is proposed to simulate the mechanical behavior of tunnel excavation and support in jointed rock.

\section{Main idea}

Based on the Continuum Discontinuum Element Method (CDEM), discrete particle clusters are used to characterize the broken rock mass inside the loosening region around the tunnel, block elements are adopted to represent the lining around the tunnel and intact rock mass outside the loosening area, and bar elements are used to denote the bolts and cables. The interpolation coupling method is used to achieve the transmission of force and displacement between the element of bars and the element of particles and blocks. The coupling method is shown in Figure 1.

* Corresponding author: fengchun@imech.ac.cn 


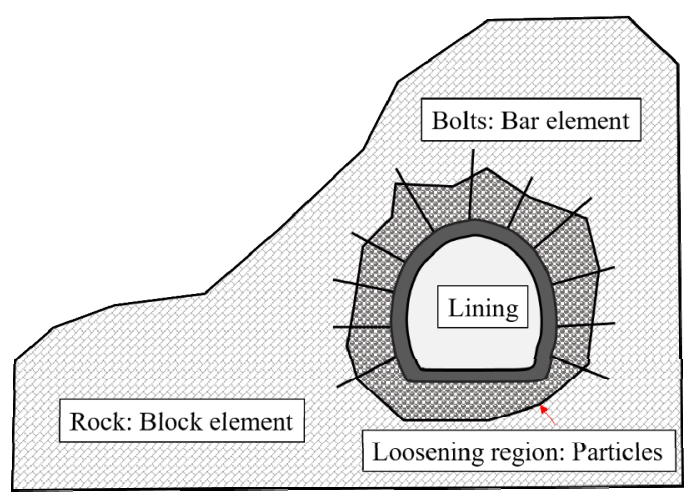

Fig. 1. The block-particle-bar coupling model

Contact coupling method is adopted between blocks and particles, and normal and tangential contact springs are constructed to transmit the normal and shear contact forces. The coupling model between blocks and particles is shown in Figure 2.

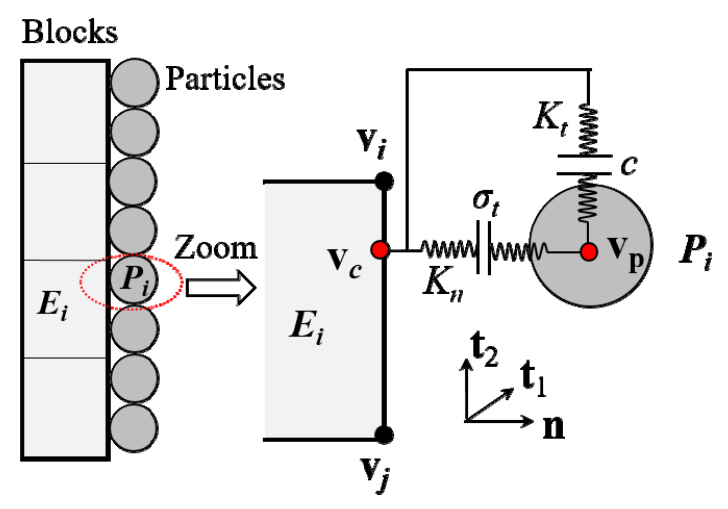

Fig. 2. Block-particle coupling model

In order to quickly create a large number of bars in complex strata and realize the coupling calculation between bars and block elements, interpolation coupling method is adopted. In this coupling way, the bars don't need to share nodes with the elements, so the modeling process is greatly simplified. The schematic diagram of interpolation coupling is shown in Figure 3.

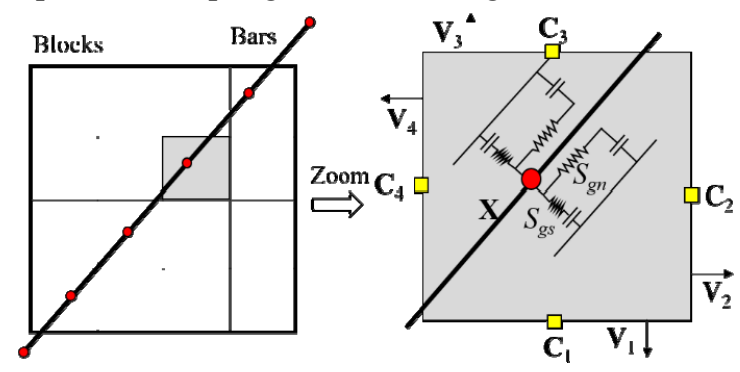

Fig. 3. Block-bar coupling model

When using prestressed bolts or cables to support surrounding rock, the prestress needs to be applied correctly. Here, an efficient way to apply such prestress is proposed (shown in Figure 4). A tensile force vector Fpre along the axis of bar is applied on the prestressed point of the bar, and the compressive force vector opposite to Fpre for ith node of the corresponding element is applied at same time.

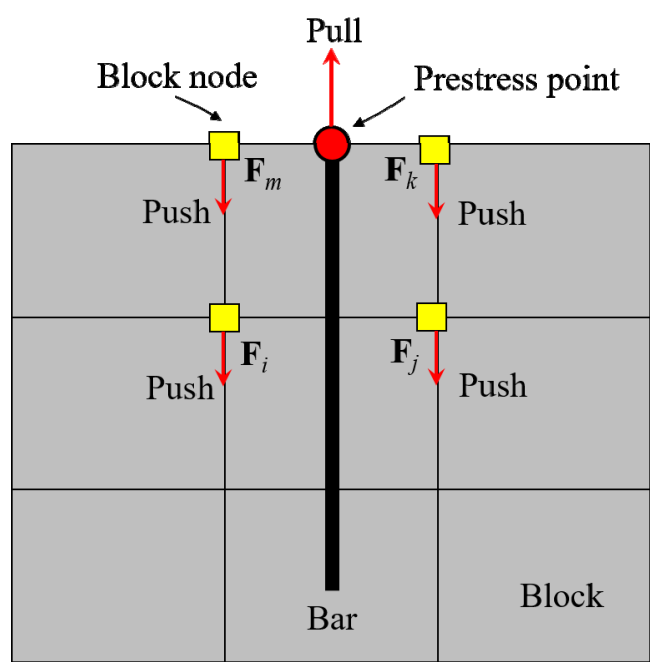

Fig. 4. Prestress applied model

Penalty spring method is still adopted to represent the relationship between particles and bar elements. The geometric relationship between bar nodes and particles should be determined firstly. Once a bar node locates in the interior of a particle, the interpolation relationship between the bar node and the particle can be established (Figure 5).

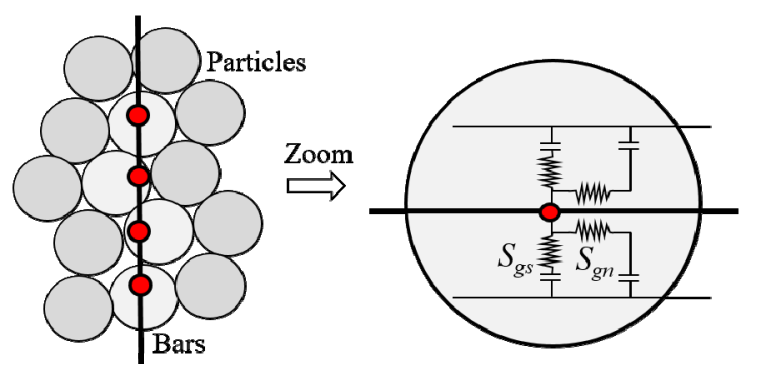

Fig. 5. Particle-bar coupling model

\section{Analysis of tunnel support effect in jointed rock mass}

The numerical tunnel model is shown in Figure 6. The external dimension of the model is $40 \mathrm{~m} \times 35 \mathrm{~m}$, and a straight wall semi-circular arch tunnel is set in the center of the model. The bottom of the tunnel is $11 \mathrm{~m}$ away from the bottom of the model. The diameter of semicircular arch is $10 \mathrm{~m}$, the height of the straight wall is $4 \mathrm{~m}$, and the lining thickness of the tunnel is $20 \mathrm{~cm}$. The tunnel is surrounded by irregular loosening zone with an average thickness of $3 \mathrm{~m}$. On the cross-section, 29 fullanchored bolts with the diameter $2 \mathrm{~cm}$ and the length 5 $\mathrm{m}$ are arranged, and the bolt spacing is $1.0 \mathrm{~m}$. The intact rock mass and tunnel lining around the tunnel are described by 14,436 finite elements, the loosening region is described by 10,011 particles, and each bolt is described by 25 bar elements. 


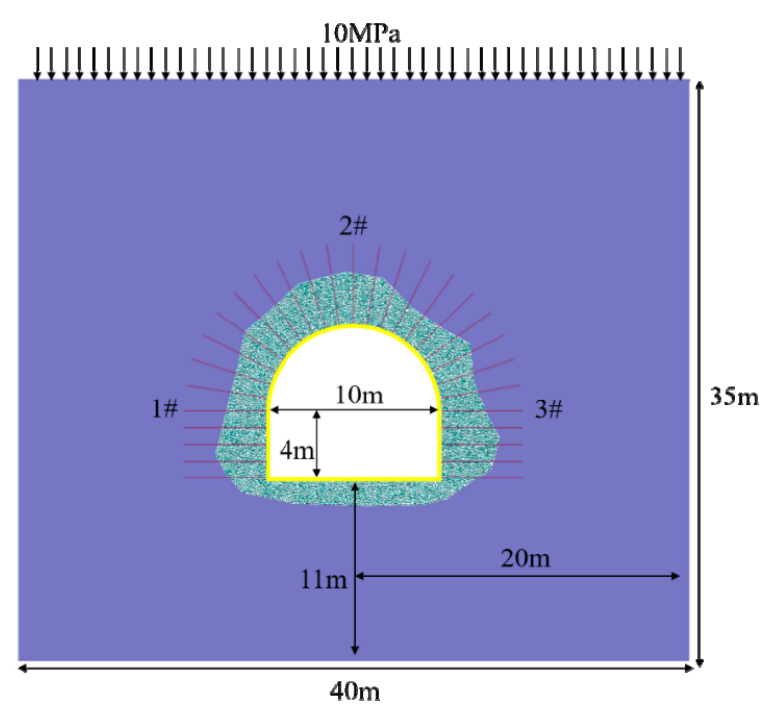

The mechanical parameters of surrounding rock, loosening zone and lining structure of the tunnel are shown in table 1 .

The physical and mechanical parameters of the rock bolts are: density $7800 \mathrm{~kg} / \mathrm{m}^{3}$, elastic modulus $210 \mathrm{GPa}$, Poisson's ratio 0.25 , the tensile and compressive strength of the bolt itself is $235 \mathrm{MPa}$, the coupling stiffness per unit length between the bolt and surrounding rock is $100 \mathrm{GPa}$, the coupling cohesion between the bolt and surrounding rock is $10 \mathrm{MPa}$, and the coupling friction coefficient is 0.7 .

Fig. 6. Tunnel excavation support model

Table 1. Mechanical parameters

\begin{tabular}{|c|c|c|c|c|c|c|c|}
\hline Materials & $\begin{array}{c}\text { Density } \\
/ \mathbf{k g m}^{3}\end{array}$ & $\begin{array}{c}\text { Elasticity } \\
\text { modulus } \\
/ \mathbf{G P a}\end{array}$ & $\begin{array}{c}\text { Poisson's } \\
\text { ratio } \\
/\end{array}$ & $\begin{array}{c}\text { Cohesion } \\
/ \mathbf{M P a}\end{array}$ & $\begin{array}{c}\text { Tensile } \\
\text { strength } \\
/ \mathbf{M P a}\end{array}$ & $\begin{array}{c}\text { Internal } \\
\text { friction } \\
\text { angle } \\
/ 0\end{array}$ & $\begin{array}{c}\text { Dilation } \\
\text { angle } \\
\mathbf{o}^{\circ}\end{array}$ \\
\hline surrounding rock & 2200 & 10 & 0.3 & 3 & 3 & 25 & 10 \\
\hline broken zone & 2200 & 5 & 0.33 & 1 & 1 & 20 & 10 \\
\hline lining structure & 2500 & 36 & 0.25 & 8 & 4 & 35 & 15 \\
\hline
\end{tabular}

In the calculation, normal constraints are applied at the bottom and all sides of the model, and $10 \mathrm{MPa}$ in-situ stress is applied at the top of the model to simulate a burial depth of $400 \mathrm{~m}$. Three cases with different support strategies were simulated, which are no support (case A), only lining support (case B), and lining-bolt coupled support (case C). The deformation and failure of the tunnel under these three cases are shown in Figure 7. According to the figure, in case $\mathrm{A}$, the loosening zone collapsed totally, and a lot of loose materials are piled up in the tunnel. In case B, although the tunnel is stable, the tunnel floor has broken obviously at both ends, and uneven uplift happens in floor, with the maximal

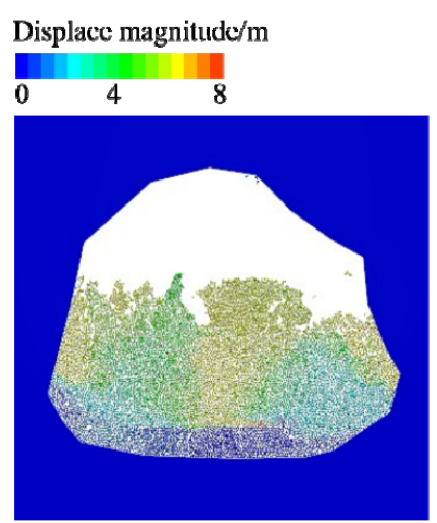

(a) Casc A

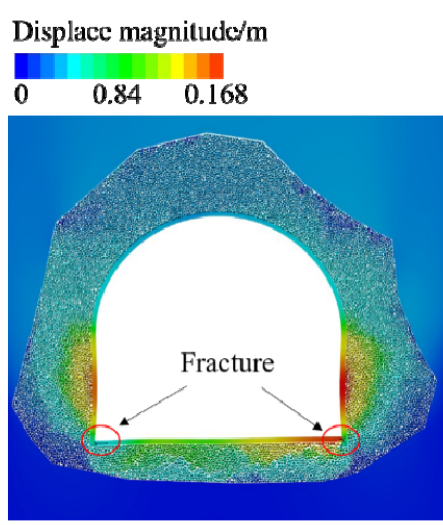

(b) Case B uplifting value $16 \mathrm{~cm}$. Besides, in case $\mathrm{B}$, the horizontal displacement of the straight walls on both sides of the tunnel is extremely large (about $17 \mathrm{~cm}$ ), and the loosening zone at the top of the tunnel is clearly separated from the surrounding rock. In case $\mathrm{C}$, the tunnel is in a stable state, and the displacement of the bottom plate, the top and the side wall are all small, which indicates that the bolts have played a role in connecting the tunnel lining with the intact surrounding rock. Due to the support of blot, the middle loosening sandwich zone is compressed by tunnel lining and intact rock, which prevents the further deformation and failure of the loose layer.

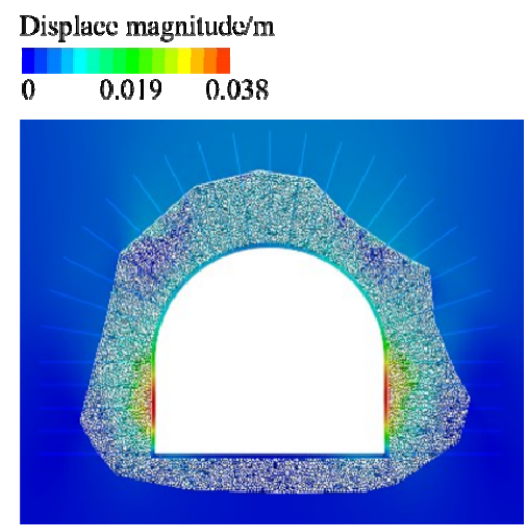

(c) Case C

Fig. 7. The displacement magnitude contour of the tunnel under three numerical cases

The axial force distribution law of the typical bolts (bolt position is shown in Figure 8) is shown in Figure 8. According to the figure, the axial force of $1 \#$ and $3 \#$ bolts is basically the same, and the whole bolt is in a tensile state. The tensile force of the $1 \#$ and $3 \#$ bolt in the loosening zone $(3 \mathrm{~m})$ is about $70 \mathrm{kN}$, however, outside 
the loosening zone, the axial force of the bolts gradually decreases to $20 \mathrm{kN}$. The 1 \# bolt is in a tension state near the tunnel lining, and the pulling force is about $70 \mathrm{kN}$; outside the lining, the axial force on the bolt is almost zero.

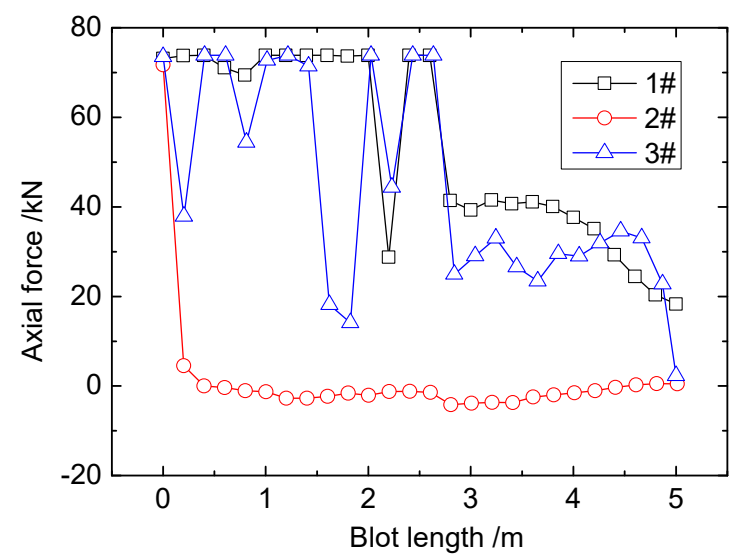

Fig. 8. The relationship between axial force and blot length

\section{Conclusions}

A block-particle-bar coupling method suitable for simulating tunnel excavation and support is proposed. By penalty springs, the transmission of force and displacement between the blocks, particles and bars is realized. The contact coupling method is adopted between blocks and particles, and one normal spring and two tangential springs are constructed to simulate the tensile and shear failure of the contact under the control of brittle Mohr-Coulomb constitutive law and tensile law. The interpolation coupling way is used to transmit displacement and force between bars and particles or blocks, penalty springs along the axis of the bar and perpendicular to the axis of the bar are established, and the pull-out effect and lateral extrusion effect between bar and rock can be considered respectively.

The coupling method described in this article is applied to simulate the tunnel excavation and support. The results of numerical cases are demonstrated to show the accuracy and rationality of the method. By this proposed coupling method, the progressive failure process of rock tunnel under high ground stress and the supporting process by lining and bolt (cable) can be accurately simulated.

\section{Funding Statement}

The research in this article was funded by National Key R\&D Program of China [No. 2018YFE0101100; No. 2018YFC1505504], Science and Technology Innovation Program of Foshan [No. BK20BE008].

\section{References}

1. Obaidur R, Jyant K. Stability analysis of twin horseshoe shaped tunnels in rock mass, Tunnelling and Underground Space Technology, 98 (2020)
2. Wu GJ, Chen WZ, Rong C, et al. Elastoplastic damage evolution constitutive model of saturated rock with respect to volumetric strain in rock and its engineering application. Tunnelling and Underground Space Technology, (2020)

3. Wasilewski S. Gas-dynamic phenomena caused by rock mass tremors and rock bursts, International Journal of Mining Science and Technology, (2020)

4. He MC, Li JY, Ren FQ. Rock burst criterion based on clay mineral content. Arabian Journal of Geosciences, 13 (4): 1-8 (2020)

5. Yang ZQ, Liu C, Zhu HZ, et al. Mechanism of rock burst caused by fracture of key strata during irregular working face mining and its prevention methods. International Journal of Mining Science and Technology, 29: 889-897 (2019)

6. Chen WT, Huan Y, Fan PX. Numerical Analysis on Minimal Safe Distance between Two Opposite Excavation Faces of Deep-Buried Tunnel. Applied Mechanics and Materials, 2545: 1315-1320 (2013)

7. Liu JC, Liu XL, Ren LW. Research and Discuss on Development of Deep Tunnel Bolt Supporting Technology. Applied Mechanics and Materials, 204208: 1542-1546 (2012)

8. Huang F, Wang Y, Wen Y, et al. The Deformation and Failure Analysis of Rock Mass Around Tunnel by Coupling Finite Difference Method and Discrete Element Method. Indian Geotechnical Journal, 49 (4):421-436 (2019)

9. Yang ZM, Wu SC, Gao YT, et al. Time and technique of rehabilitation for large deformation of tunnels in jointed rock masses based on FDM and DEM numerical modeling. Tunnelling and Underground Space Technology, 81: 669-681. (2018)

10. Saiang D. Stability analysis of the blast-induced damage zone by continuum and coupled continuumdiscontinuum methods. engineering geology, 116(12):1-11 (2010)

11. Lisjak A, Grasselli G, Vietor T. Continuumdiscontinuum analysis of failure mechanisms around unsupported circular excavations in anisotropic clay shales. International Journal of Rock Mechanics and Mining Sciences, 65:96-115 (2014)

12. Liu QS, Xu XY, Wu ZJ. A GPU-based numerical manifold method for modeling the formation of the excavation damaged zone in deep rock tunnels. Computers and Geotechnics. 118 (2020) 